\title{
Comparative Study on Grating Fabrication in Transparent Materials by TWIN-LIBWE and Ultrashort Pulsed Ablation Techniques
}

\author{
Csaba VASS ${ }^{* 1}$, Bálint KISS ${ }^{* 1,2}$, Roland FLENDER ${ }^{* 1}$, Zoltán FELHÁZI ${ }^{* 1}$, Pierre LORENZ ${ }^{* 3}$, Martin EHRHARDT ${ }^{* 3}$, Klaus \\ ZIMMER $^{* 3}$ \\ ${ }^{* 1}$ Department of Optics and Quantum Electronics, University of Szeged, H-6720 Szeged, Dóm tér 9, \\ Hungary \\ E-mail: vasscsaba@physx.u-szeged.hu \\ ${ }^{* 2}$ ELI-Hu Nkft., Dugonics ter 13, H-6720 Szeged, Hungary \\ ${ }^{* 3}$ Leibniz-Institut für Oberflächenmodifizierung e. V., Permoserstraße 15, 04318 Leipzig, Germany
}

\begin{abstract}
Two methods for micro-structuring of transparent dielectric were compared in this study: the two-beam interferometric laser-induced backside wet etching (TWIN-LIBWE) and the two beam interferometric ablation by ultrashort laser pulses. In TWIN-LIBWE we used the $4^{\text {th }}$ harmonic of Nd:YAG laser $\left(\lambda=266 \mathrm{~nm}, \tau_{F W H M}=8 \mathrm{~ns}\right.$, fuence: $\left.265-500 \mathrm{~mJ} / \mathrm{cm}^{2}\right)$, while a Ti:Sapphire-based femtosecond system ( $\lambda=800 \mathrm{~nm}, \tau_{F W H M}=30 \mathrm{fs}$, pulse energy: $\left.600-900 \mu \mathrm{J}\right)$ was used for direct ablation. Fused silica, sapphire and glass were used as bulk targets, while $\mathrm{Al}_{2} \mathrm{O}_{3}, \mathrm{Y}_{2} \mathrm{O}_{3}, \mathrm{HfO}_{2}$ and $\mathrm{ZrO}_{2}$ thin films (thickness: $160-1000 \mathrm{~nm}$ ) on fused silica substrates were used as transparent film targets. The incident angle of the interfering beams was adjusted to result in $1 \mu \mathrm{m}$ period structures in both arrangements. The surface morphologies of gratings were studied by atomic force microscope (AFM). After the comparison of best quality gratings produced by both setup in each material, we cannot determined which is the universally optimal method. The grating quality depends on the target material, their thickness, and certainly on the laser parameter.
\end{abstract}

DOI: $10.2961 /$ jlmn.2015.01.0008

Keywords: grating fabrication, transparent dielectric, two-beam interference, TWIN-LIBWE, ultrashort laser ablation

\section{Introduction}

The microstructured transparent materials have many application possibilities in optics, laser physics and biosensing [1-3].

The transparent dielectric materials can be microstructured by conventional, masking-based techniques (multistep methods): chemical (hidrofluidic) etching [4], powder blasting [5-6] and ion etching technologies (inductively coupled plasma etching - ICP [7] and reactive ion etching - RIE [8]). Hidrofluidic etching and powder blasting have limited resolution (some ten micrometer) and the machined surface is not smooth enough for special applications. RIE can reach submicron resolution and high quality, smooth processed surface, but it is a very complicated and expensive multistep procedure.

The laser based techniques could provide good alternative for structuring of transparent materials, but the transparency of target material cause difficulties, since the effective material removal is not trivial, due to the low absorption coefficient of targets. The laser-based techniques can be divided into direct and indirect techniques. In the direct methods infrared and far ultraviolet lasers $\left(\mathrm{CO}_{2}[9], \mathrm{F}_{2}[10-\right.$ $11])$, soft X-ray beam [12] and femtosecond pulses [11, 1314] can be used for etching. Although the $\mathrm{CO}_{2}$ laser is applied in industrial environments, but the reachable resolution is some ten micrometer (due to its long wavelength $(10.6 \mu \mathrm{m})$ and thermal based material removal), which is not sufficient for microoptical applications. However, the other direct methods $\left(\mathrm{F}_{2}\right.$ laser and soft $\mathrm{X}$-ray) provides good quality, they are too complicated at present for real industrial applications. The nanosecond UV lasers would be suitable for micromachining of UV-transparent materials, but the effectiveness and the surface quality is rather low. The ultrashort laser pulses provide promising results in materials structuring.

The indirect laser-based methods, the laser-induced backside wet/dry etching - LIBWE/LIBDE [15-23], laser etching at a surface adsorbed layer - LESAL [24] and laser induced plasma assisted ablation - LIPAA [25] are mainly based on UV (excimer) lasers, which has already proved its suitability in industrial environments and provide the sufficient resolution.

In this study our aim was to compare the most flexible and promising indirect technique, the laser-induced backside wet etching (LIBWE), and the ultrashort pulse ablation. We produced $1 \mu \mathrm{m}$ period grating structures by these techniques in two-beam interferometric arrangement into different transparent bulk and thin film materials. The laser parameters were optimized in each setup and method, and the morphology of the best quality grating was compared.

\section{Experimental}

In our first experiment series a Q-switched, frequencyquadrupled nanosecond Nd:YAG laser $\left(\lambda=266 \mathrm{~nm} ; \tau_{\text {FWHM }}=8\right.$ ns, repetition rate: $10 \mathrm{~Hz}$ ) was used in the two-beam interference arrangement. The intensity profile of the laser beam was smoothed by two spatial filters in green and in UV. The $s$-polarized, collimated beam was splitted into two 
parts with equal intensities, which were steered by dielectric mirrors at $\theta=7.64^{\circ}$ incident angle onto the backside surface of target (Fig. 1) resulted in $1 \mu \mathrm{m}$ period interference pattern, which was etched into the target by TWINLIBWE (two-beam interferometric LIBWE) mechanism. Naphthalene and methyl-methacrylate solution with $\mathrm{c}=1.71$ $\mathrm{mol} / \mathrm{dm}^{3}$ concentration (saturated solution) was used as liquid absorbent, which is essential for material removal by LIBWE method [16,19].

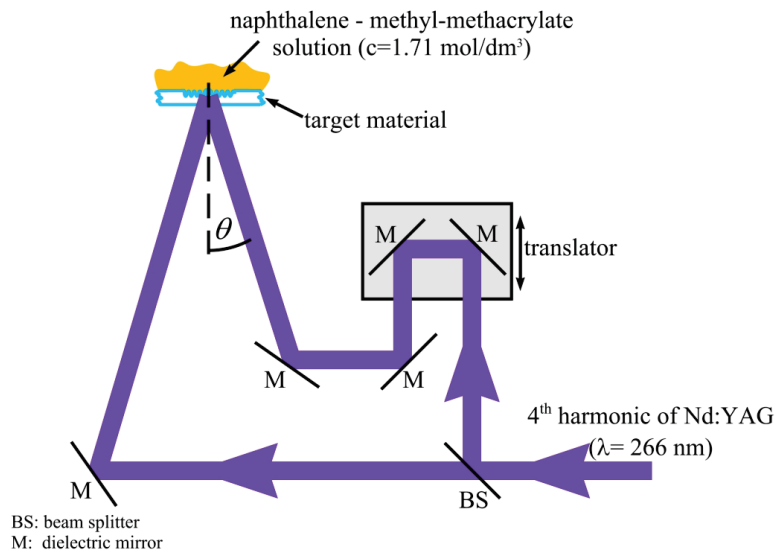

Fig. 1 Scheme of nanosecond laser-based TWIN-LIBWE setup

The coherence length of the laser was measured to be $\approx 15$ $\mathrm{mm}$. The equal beam path was adjusted by the delay stage with maximizing the modulation depth of the produced grating. The applied laser fluence was varied between 230 and $550 \mathrm{~mJ} / \mathrm{cm}^{2}$, while the number of laser pulses was up to 150 pulses. The irradiated spot diameter was approx. 0.5 $\mathrm{mm}$.

In the second experiment sequence a Ti:Sapphire-based ultrashort laser system ( $\lambda=800 \mathrm{~nm} ; \tau_{\text {FWHM }}=30 \mathrm{fs}$, repetition rate: $200 \mathrm{~Hz}$ ) was used in also two-beam interferometric arrangement. The chirped pulses of Rainbow CEP4 type (Femtolasers) oscillator was amplified in a single stage by a multipass Ti:Sapphire amplifier. The energy of compressed pulses was $600-900 \mu \mathrm{J}$, and the beam diameter was $5 \mathrm{~mm}$. In order to increase the fluence of the interfering beams to the desired level, both beams were focused to the target (Fig.2) by silver coated spherical mirrors $(f=250$ $\mathrm{mm})$. The diameter of the irradiated spot during the ablation was below $100 \mu \mathrm{m}$, in all cases.

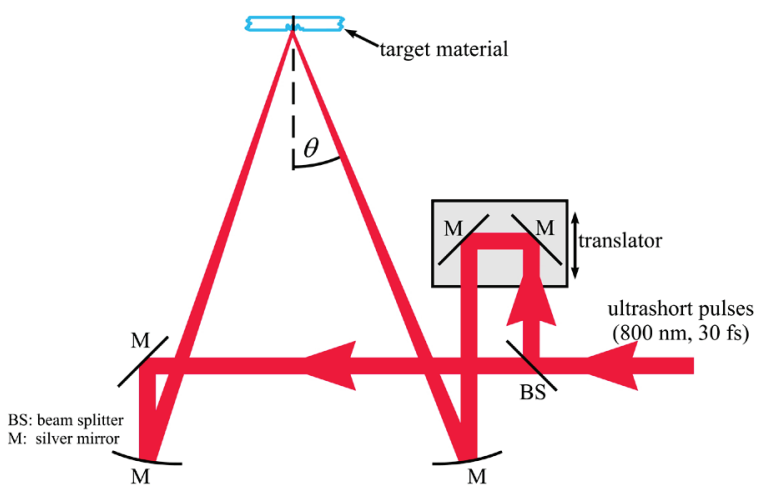

Fig. 2 Scheme of femtosecond laser-based two-beam interferometric setup
The temporal overlapping of the interfering pulses was set by the observation of nonlinear effect induced in the target. The interfering beams were again $s$-polarized, the incident angle was $\theta=23.58^{\circ}$ on the front side of target resulted in 1 $\mu \mathrm{m}$ period gratings, similar to nanosecond case.

The targets were bulk transparent dielectrics and thin films for the comparison of two techniques. Fused silica, sapphire and glass targets were used as bulk target having dimension of $25 \mathrm{~mm} \mathrm{X} 25 \mathrm{~mm}$ with thickness of $1 \mathrm{~mm}$. The thin film targets were $\mathrm{Al}_{2} \mathrm{O}_{3}, \mathrm{Y}_{2} \mathrm{O}_{3}, \mathrm{HfO}_{2}$ and $\mathrm{ZrO}_{2}$ deposited on fused silica substrates.

The morphology of the gratings was studied by a PSIA XE-100 atomic force microscope (AFM) in non-contact mode. Additionally, a Dektak 8 profilometer was applied to help to decide if the grating is solely produced in the dielectric film. We focused only on those structures which etched into the films only, leaving the substrate unmodified under them.

\section{Results and discussion}

We optimized the laser parameters (laser fluence and number of pulses) for each material in both experimental setups. Only the optimal (grooves are solely in films), best quality gratings are shown in this study. The optimizing method was same as presented in our previous study [26].

\subsection{Bulk targets}

The fused silica grating fabrication by TWIN-LIBWE method was well-studied and described topic [1, 27-30]. For an example a high quality grating produced by TWINLIBWE can be seen in Fig. 3a. The optimal laser fluence is between the threshold and the double of etching threshold, while the pulse number can be varied up to 100 pulses, depending on the demanded modulation depth.
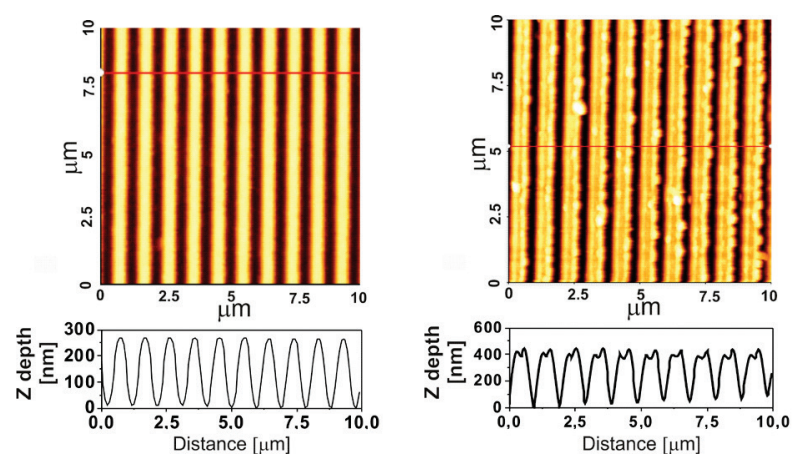

Fig. 3 AFM images of fused silica gratings produced by (a) TWIN-LIBWE (laser fluence: $390 \mathrm{~mJ} / \mathrm{cm}^{2} ; 75$ pulses) (b) ultrashort ablation $(770 \mu \mathrm{J}, 1$ pulse $)$

In the femtosecond direct ablation case of fused silica the gratings contain some debris-like formation (Fig. 3b), and the groves are not so regular than at nanosecond laser based TWIN-LIBWE arrangement. Using more than 10 pulses the ablated hole became a few micrometers deep in this arrangement, and the grating quality gradually decreases with increasing pulse quantity.

The sapphire is also an important UV transparent material, which was also microstructured by our methods. The grating quality is similar for both methods, and the modulation depths $(M D)$ are in same magnitude $\left(M D_{n s}=50 \mathrm{~nm}\right.$; $M D_{f s}=30 \mathrm{~nm}$ ) (Fig. 4). 

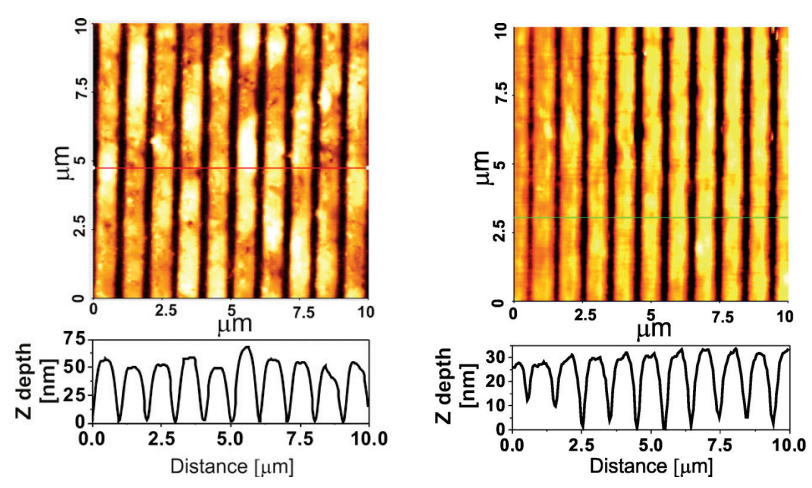

Fig. 4 AFM images of sapphire gratings produced by (a) TWIN-LIBWE (laser fluence: $370 \mathrm{~mJ} / \mathrm{cm}^{2} ; 60$ pulses)

(b) ultrashort ablation $(600 \mu \mathrm{J}, 6$ pulses $)$

The grooves are not as regular as in the case of fused silica, and the reachable MD is significantly lower as well. This behavior is probably correlated with the different material properties (thermal, mechanical and optical parameters) of sapphire and fused silica. For example the heat diffusion lengths ( $L=2 \sqrt{D \tau}$, where $D$ is heat diffusivity, and $\tau$ is laser beam dwell time [31]) of sapphire for nanosecond pulses is four times higher than of fused silica $\left(L_{\text {fused sili- }}\right.$ $\left.{ }_{c a}=167 \mathrm{~nm}, L_{\text {sapphire }}=632 \mathrm{~nm}\right)$, which parameter can be partially interpret the difference. Beside the thermal parameters, the optical and mechanical properties difference also can contribute to the different results obtained.

The third tested bulk material was the glass, which is not transparent in the UV, which property makes it unsuitable target for TWIN-LIBWE technique. For this reason gratings were fabricated only by femtosecond laser ablation.

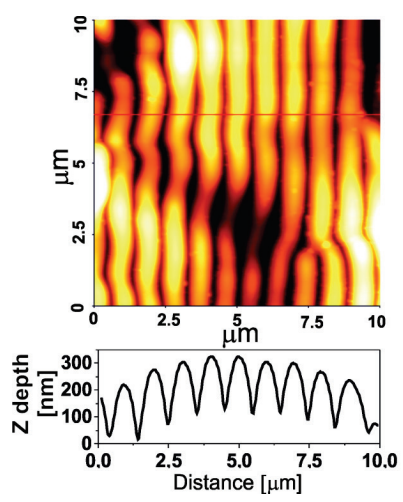

Fig. 5 AFM image of glass grating produced by ultrashort ablation $(600 \mu \mathrm{J}, 10$ pulses $)$

The quality of glass surface relief grating is rather poor (Fig. 5): the grooves are bended and become irregular, which refer melting and thermal processes could take place during ablation. This effect is similar to previously observed phenomenon in the case of TWIN-LIBWE of fused silica applying high laser fluence and/or high pulse number (see Fig 2. in ref [27]).

\subsection{Thin film targets}

Generally, the optimal laser parameter set for high quality grating fabrication into transparent films by TWINLIBWE is significantly narrower than in case of bulk tar- gets. The optimal fluence is just above the etching threshold (opposite to the relative wide fluence range for bulk fused silica: $285-600 \mathrm{~mJ} / \mathrm{cm}^{2}$ ), while the pulse number have to be below 10 [26]. The detailed interpretation of the following result is difficult, since we do not know the real properties of the films (compactness of films (and therefore the real thermal and mechanical properties), the adhesion to the fused silica substrate etc.).

One of the most promising structured dielectric materials for biosensing applications is the $\mathbf{A l}_{\mathbf{2}} \mathbf{O}_{\mathbf{3}}$ film [26]. Two different films were processed with different thickness, which were 300 and $1000 \mathrm{~nm}$, respectively. High quality gratings were produced by TWIN-LIBWE, as it can be seen in AFM images in Fig. 6a and 7a. Using this method fluence above $>300 \mathrm{~mJ} / \mathrm{cm}^{2}$ resulted cracks on the irradiated surface.
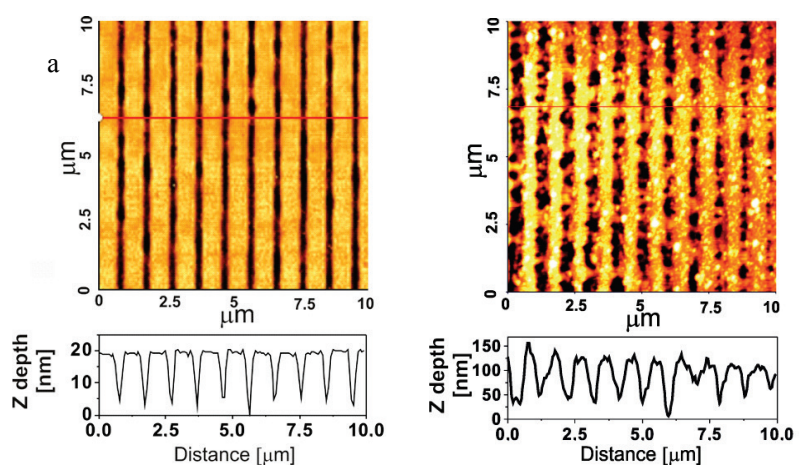

Fig. 6 AFM images of gratings produced in $\mathrm{Al}_{2} \mathrm{O}_{3}$ film (300 nm thickness) by

(a) TWIN-LIBWE (laser fluence: $260 \mathrm{~mJ} / \mathrm{cm}^{2} ; 3$ pulses)

(b) ultrashort ablation $(600 \mu \mathrm{J}, 2$ pulses $)$

In case of ultrashort ablation of thinner $\mathrm{Al}_{2} \mathrm{O}_{3}$ film, the quality is much lower than using TWIN-LIBWE, debris can be observed in AFM image (Fig. 6b), however the modulation depth is higher than in indirect etching case (20 $\mathrm{nm}$ vs. $100 \mathrm{~nm}$ ). If the number of applied ultrashort pulses more than two, the film completely peels off from the fused silica surface, independently from the film thickness.
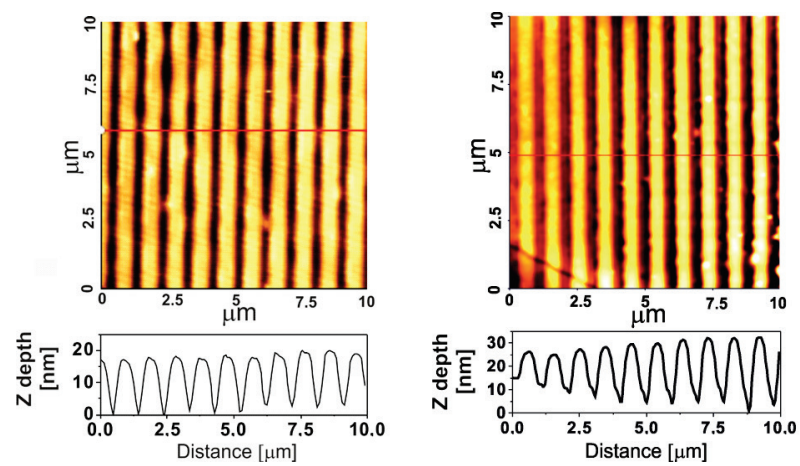

Fig. 7 AFM images of gratings produced in $\mathrm{Al}_{2} \mathrm{O}_{3}$ film (1000 nm thickness) by

(a) TWIN-LIBWE (laser fluence: $250 \mathrm{~mJ} / \mathrm{cm}^{2} ; 10$ pulses)

(b) ultrashort ablation $(600 \mu \mathrm{J}, 2$ pulses $)$

In contrast with the results achieved on the thinner $\mathrm{Al}_{2} \mathrm{O}_{3}$ film, high quality structures can be produced in the thicker film by ultrashort pulses (Fig. 7b): the quality and the 
modulation depth are similar to the indirect etching case (Fig. 7a).

Although the grating quality fabricated in $\mathbf{Y}_{2} \mathbf{O}_{3}$ film (thickness: $200 \mathrm{~nm}$ ) by TWIN-LIBWE is acceptable for sensoric applications (Fig. 8a) [26], however the ultrashort ablation of this film is not suitable to produce usable grating structure: one pulse is insufficient for any observable modification or etching, but two pulses partially removed the film (Fig. 8b).
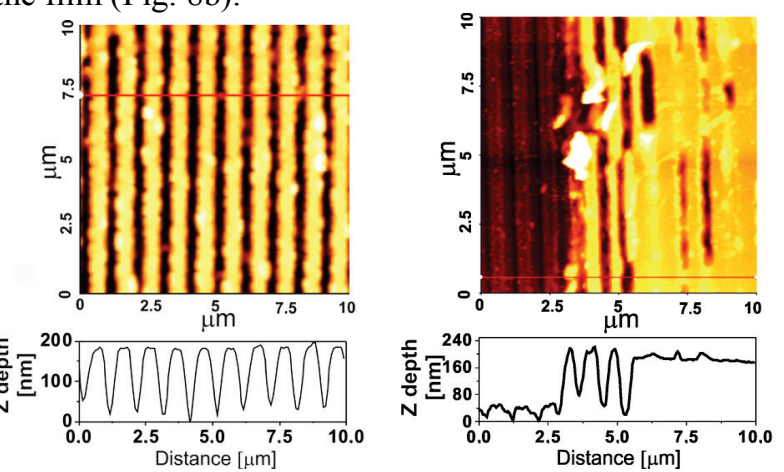

Fig. 8 AFM images of gratings produced in $\mathrm{Y}_{2} \mathrm{O}_{3}$ film (200 nm thickness) by

(a) TWIN-LIBWE (laser fluence: $260 \mathrm{~mJ} / \mathrm{cm}^{2} ; 8$ pulses)

(b) ultrashort ablation $(600 \mu \mathrm{J}, 2$ pulses $)$

Only the surrounding area of peeled off film was grooved: the diameter of the structured area is only a few periods wide, which is not sufficient for applications. In Fig. $8 \mathrm{~b}$ the left side of AFM image the slightly grooved fused silica substrate can be seen; in the center part a few period wide grooved area can be observed, while on the right side contains intrinsically unetched $\mathrm{Y}_{2} \mathrm{O}_{3}$ film. We conclude that the ultrashort ablation cannot be applied for grating fabrication, while TWIN-LIBWE is applicable for microstructuring of $\mathrm{Y}_{2} \mathrm{O}_{3}$ film.

$\mathrm{HfO}_{2}$ film is widely used in multilayer coatings of optical materials. In the case of TWIN-LIBWE the partially peeled off structured areas are inevitable phenomena in spite of trying all relevant laser parameter sets (Fig. 9a).
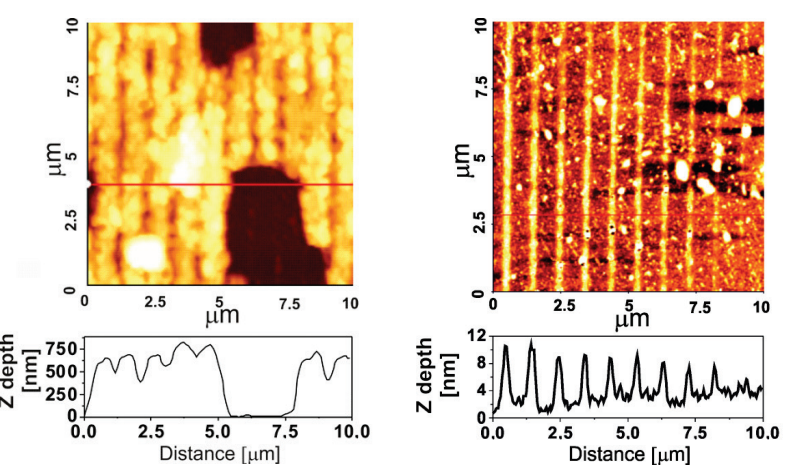

Fig. 9 AFM images of gratings produced in $\mathrm{HfO}_{2}$ film (620 nm thickness) by

(a) TWIN-LIBWE (laser fluence: $350 \mathrm{~mJ} / \mathrm{cm}^{2} ; 10$ pulses)

(b) ultrashort ablation $(600 \mu \mathrm{J}, 2$ pulses $)$

The complete removal of film is also observed above 2 pulses in case of ablation. The presented AFM image shows small swelled grooves (Fig. 9b), which refer to incubation effect. But the further pulse(s) completely remove the film, instead of its structuring. Unfortunately, none of the presented methods can be structured the $\mathrm{HfO}_{2}$ film.

Our final experiments were the grating fabrication in $\mathbf{Z r O}_{2}$ film (thickness: $160 \mathrm{~nm}$ ). The TWIN-LIBWE resulted in debris deposition on the grooved surface, and the grooves are rather irregular (Fig. 10a).
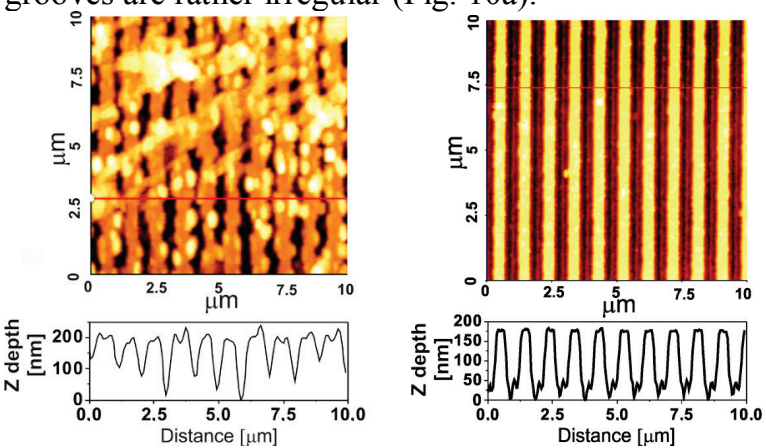

Fig. 10 AFM images of gratings produced in $\mathrm{ZrO}_{2}$ film (160 nm thickness) by

(a) TWIN-LIBWE (laser fluence: $235 \mathrm{~mJ} / \mathrm{cm}^{2} ; 10$ pulses)

(b) ultrashort ablation $(600 \mu \mathrm{J}, 1$ pulses $)$

In contrast, the application of ultrashort laser-based twobeam interference arrangement resulted in high quality grating structures in $\mathrm{ZrO}_{2}$ films (Fig. 10b).

\section{Summary and conclusion}

After the fabrication of some hundred grooved spots with both setups, we have rather certain impressions about the main advantages and difficulties of the two experimental arrangements. The most important parameters are summarized in Table 1.

Table 1 Comparison of our two arrangement for microstructuring of transparent materials (TWIN LIBWE versus ultrashort laser-based ablation)

\begin{tabular}{lcc}
\hline & $\begin{array}{c}\text { TWIN- } \\
\text { LIBWE }\end{array}$ & $\begin{array}{c}\text { Ultrashort } \\
\text { pulse ablation }\end{array}$ \\
\hline Laser system & $\begin{array}{c}\text { simple } \\
\text { (nanosecond) } \\
\text { relatively } \\
\text { simple } \\
\text { chamber, } \\
\text { Building up the setup - adjusting } \\
\text { equal beam path }\end{array}$ & $\begin{array}{c}\text { complicated } \\
\text { (femtosecond) }\end{array}$ \\
$\begin{array}{l}\text { difficult } \\
\text { chemicals }\end{array}$ & \\
$\begin{array}{l}\text { Resolution } \\
\text { (determined by the wavelength) }\end{array}$ & $\sim 100 \mathrm{~nm}$ & $4-500 \mathrm{~nm}$ \\
$\begin{array}{l}\text { Processed area (diameter) } \\
\begin{array}{l}\text { Optimal number of laser pulses } \\
\text { (depends on the target material) }\end{array}\end{array}$ & $\approx 0.5 \mathrm{~mm}$ & $<0.1 \mathrm{~mm}$ \\
\hline
\end{tabular}

The final question is obvious: which studied technique is the best method for microstructuring of UV transparent dielectric. According to our results, the answer is not evident: it depends on the aims (e.g. grooved area, required resolution, etc.), on the material, which have to structure, and on the possibilities, infrastructure of the laboratory (available laser, chemicals etc.). 


\section{Acknowledgments}

The authors gratefully acknowledge the financial support of Hungarian Scientific Research Fund (OTKA PD 104477). This research was supported by the European Union and the State of Hungary, co-financed by the European Social Fund in the framework of TÁMOP 4.2.4. A/211-1-2012-0001 'National Excellence Program. The project was subsidized by the European Union and co-financed by the European Social Fund. The project was partially funded by DAAD (no.:56266271) and „TÁMOP-4.2.2.A11/1/KONV-2012-0060 - „Pulse lasers for use in materials science and biophotonics" is supported by the European Union and co-financed by the European Social Fund.

\section{References}

[1] B. Kiss, C. Vass, P Heck, P Dombi and K Osvay: J. Phys. D: Appl. Phys., 44, (2011) 415103.

[2] J. Voros, R. Graf, G.L. Kenausis, A. Bruinink, J. Mayer, M. Textor, E. Wintermantel and N.D. Spencer: Biosens. Bioelectron., 15, (2000) 423.

[3] J. Voros, J.J. Ramsden, G. Csucs, I. Szendro, S.M. De Paula, M. Textora and N.D. Spencer: Biomater., 23, (2002) 3699.

[4] M. Bu, T. Melvin, G. J. Ensell, J. S. Wilkinson and A. G.R. Evans: Sens. Actuators A, 115, (2004) 476.

[5] E. Belloy, S. Thurre, E. Walckiers, A. Sayah and M.A.M Gijs: Sens. Actuators, 84, (2000) 330.

[6] H.-S. Jang, M.-W. Cho and D.-S. Park: Sensors, 8, (2008) 700 .

[7] S. Wang, C. Zhou, H. Ru, and Y. Zhang: Appl. Opt., $44,(2004) 4429$.

[8] X. Lia, T. Abeb and M. Esashi: Sens. Actuators. A, 87, (2001) 139.

[9] M.-H. Yen, J.-Y. Cheng, C.-W. Wei, Y.-C. Chuang and T.-H. Young: J. Micromech. Microeng., 16, (2006) 1143.

[10] J. Ihlemann, S. Müller, S. Puschmann, D. Schäfer, M. Wei, J. Li and P.R. Herman: Appl. Phys., A, 76 (2003) 751.

[11]P.R. Herman, R.S. Marjoribanks, A. Oettl, K. Chen, I. Konovalov and S. Ness: Appl. Surf. Sci., 154-155, (2000) 577.
[12] T. Makimura, S. Mitani, Y. Kenmotsu, K. Murakami, M. Mori and K. Kondo: Appl. Phys. Let.. 85. (2004) 1274.

[13] J. Ihlemann, B. Wolff, and P. Simon: Appl. Phys. A. 54. (1992) 363.

[14] K. Kawamura, N. Sarukura, M. Hirano and H. Hosono: Appl. Phys. Lett., 78, (2001) 1038.

[15] S. I. Dolgaev, A. A. Lyalin, A. V. Simakin and G. A. Shafeev: Appl. Surf. Sci.. 96-98. (1996) 491.

[16] J. Wang, H. Niino and A. Yabe: Appl. Phys. A, 68, (1999) 111.

[17]R. Böhme, A. Braun and K. Zimmer: Appl. Surf. Sci., 186, (2002) 276.

[18] G. Kopitkovas, T. Lippert, C. David, A. Wokaun and J. Gobrecht: Micromech. Microeng., 67-68, (2003) 438.

[19] Cs. Vass, B. Hopp, T. Smausz, F. Ignácz: Thin Solid Films, 453 -454, (2004) 121

[20] J.-Y. Cheng, M.-H. Yen, C.-W. Wei, Y.-C. Chuang and T.-H. Young: J. Micromech. Microeng., 15, (2005) 1147.

[21]Z.Q. Huang, M.H. Hong, T.B.M. Do and Q.Y. Lin: Appl Phys A, 93, (2008) 159.

[22] K. Fujito, T. Hashimoto, K. Samonji, J. S. Speck and S. Nakamura: J. Cryst. Growth, 272, (2004) 370.

[23]B. Hopp, Cs. Vass and T. Smausz: Appl. Surf. Sci., 253, (2007) 7922.

[24] K. Zimmer, R. Böhme and B. Rauschenbach: Appl. Phys. A, 79, (2004) 1883.

[25] J. Zhang, K. Sugioka and K. Midorikawa: Appl. Phys. A, 67, (1998) 499.

[26] B. Kiss, F. Ujhelyi, Á. Sipos, B. Farkas, P. Dombi, K. Osvay and Cs. Vass: JLMN, Vol. 8, No. 3 (2013) 271.

[27] Cs. Vass, K. Osvay, M. Csete and B. Hopp: Appl. Surf. Sci., 253, (2007) 8059.

[28] Cs. Vass, K. Osvay and B. Hopp: Opt. Express, Vol. 14, No. 18, (2006) 8354.

[29] Cs. Vass, K. Osvay, B. Hopp and Zs. Bor: Appl Phys A-Mater, 87, (2007) 611.

[30] Cs. Vass, K. Osvay, T. Véső and B. Hopp: Appl Phys A-Mater, 93, (2008) 69.

[31]D. Bäuerle, Laser Processing and Chemistry, 3rd edn. (Springer, Berlin, 2000) p.20.

(Received: July 18, 2014, Accepted: December 11, 2014) 